\title{
siRNA Targeting against EGFR, a Promising Candidate for a Novel Therapeutic Application to Lung Adenocarcinoma
}

\author{
Sumitaka Yamanaka ${ }^{a, b}$ Zhaodi Gu ${ }^{a}$ Masami Sato ${ }^{a, b}$ d Rumi Fujisaki $^{a}$ \\ Kenichi Inomata ${ }^{a}$ Akira Sakurada $^{b}$ Akira Inoue ${ }^{c}$ Toshihiro Nukiwa ${ }^{c}$ \\ Takashi Kondo ${ }^{\text {b }}$ Akira Horii ${ }^{a}$

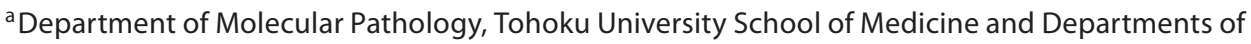 \\ ${ }^{b}$ Thoracic Surgery and ' Respiratory Oncology and Molecular Medicine, Institute of Development, Aging, and Cancer, \\ Tohoku University, Sendai, and ${ }^{\mathrm{d}}$ Division of Thoracic Surgery, Miyagi Cancer Center Hospital, Natori, Japan
}

\section{Key Words}

Epidermal growth factor receptor $\cdot$ Gefitinib $\cdot$ Lung

cancer $\cdot$ siRNA

\begin{abstract}
Objective: To understand the molecular pathogenesis of lung cancer and to establish a novel therapeutic application, we examined the genetic alterations in lung cancer, and studied the effects of gefitinib and siRNA-mediated knockdown of EGFR on lung cancer. Methods: We analyzed mutations in EGFR, KRAS, TP53, and ERBB2 in 198 surgically resected lung cancer specimens. We then analyzed the effects of gefitinib and siRNA treatment on lung adenocarcinoma cell lines. Results: Mutations in EGFR were found only in adenocarcinoma (35 of 106 adenocarcinoma), mainly in females (73\%). Mutually exclusive mutations of EGFR and KRAS genes were observed. Mutations of EGFR were well associated with a positive response to gefitinib. Cells with EGFR mutations were very sensitive to gefitinib as well as siRNA-mediated knockdown of EGFR, those with KRAS mutations responded poorly, and those without mutations of KRAS and EGFR showed moderate responses to both treatments. Conclusions: Our present results imply that (1) mutation analyses of EGFR and KRAS provide valuable information about whether or not to apply treatments targeting against EGFR and the selection of dosage for such treatments, and (2) siRNA-medi-
\end{abstract}

ated knockdown is effective in lung adenocarcinomas with EGFR mutation, probably in those with resistance to gefitinib by acquired mutation in EGFR. Copyright $\odot 2008$ s. Karger AG, Basel

\section{Introduction}

Recently, lung cancer has become the most frequent cause of cancer death worldwide [1]. In Japan, the number of cancer deaths from this disease accounts for $19.1 \%$ of the total, and it is the leading cause of cancer-related death in 2005 (http://ganjoho.ncc.go.jp/professional/statistics/statistics.html). The mean 5-year survival rate of this disease in Japan is only $14.9 \%$ (http://www.mc.pref. osaka.jp/ocr_e/ocr/survival.xls). Hence, the establishment of more effective methods for the treatment of patients with this disease is an urgent task with the highest priority. Although various refinements of the conventional therapies for lung cancer such as surgery, radiotherapy, chemotherapy, and their multidisciplinary applications have been tried, the improvement in the survival rateremainsfar from satisfactory. A newly developed, molecular-targeted antitumor drug, gefitinib (Iressa, AstraZeneca Pharmaceuticals, Macclesfield, UK), has recently become one of the main foci of the researchers' attention. Gefitinib interacts with the ATP cleft within

\section{KARGER}

Fax +41613061234 E-Mail karger@karger.ch www.karger.com
(C) 2008 S. Karger AG, Basel

$1015-2008 / 08 / 0751-0002 \$ 24.50 / 0$

Accessible online at:

www.karger.com/pat
Dr. Akira Horii

Department of Molecular Pathology

Tohoku University School of Medicine, 2-1 Seiryo-machi, Aoba-ku Sendai 980-8575 (Japan)

Tel. +81 22717 8042, Fax +81 22717 8047, E-Mail horii@mail.tains.tohoku.ac.jp 
Table 1. Nucleotide sequences of the primer sets and PCR conditions

\begin{tabular}{lllll}
\hline Name & Forward primer 5' to 3' & Reverse primer 5' to 3' & $\begin{array}{l}\text { Size of } \\
\text { product } \\
\text { bp }\end{array}$ & $\begin{array}{l}\text { Annealing } \\
\text { temperature } \\
{ }^{\circ} \mathrm{C}\end{array}$ \\
\hline EGFR exon 18 & AGCTTGTGGAGCCTCTTACACC & CTGTGCCAGGGACCTTACCT & 143 & 60 \\
EGFR exon 19 & CCATCTCACAATTGCCAGTT & ATCGAGGATTTCCTTGTTG & 146 & 60 \\
EGFR exon 21 & GTGAAAACACCGCAGCATGT & TGTCAGGAAAATGCTGGCTG & 133 & 55 \\
ERBB2 exon 20 & GTGTGTGGTCTCCCATACCCT & CCGTGGATGTCAGGCAGAT & 116 & 60 \\
KRAS exon 2 & AGGCCTGCTGAAAATGACTG & CCTCTATTGTTGGATCATATTC & 125 & 55 \\
TP53 exon 5 & CGTGTTCCAGTTGCTTTATC & CAATCAGTGAGGAATCAGAG & 328 & 60 \\
TP53 exon 6 & AGAGACGACAGGGCTGGTT & CACTGACAACCACCCTTAAC & 230 & 60 \\
TP53 exon 7 & CTGCTTGCCACAGGTCTCC & ATGGAAGAAATCGGTAAG & 268 & 60 \\
TP53 exon 8 & GACAGGTAGGACCTGATTTC & TGAATCTGAGGCATAACTGCA & 256 & 60 \\
\hline
\end{tabular}

the tyrosine kinase domain of the epidermal growth factor receptor (EGFR) and inactivates its tyrosine kinase activity, resulting in downregulation of downstream effectors [2]. Several clinical trials have indicated that the patients who enjoy benefits from gefitinib were nonsmoking Japanese female adenocarcinoma patients $[2,3]$. Recently, other studies have found that such gefitinib-responsive cases harbor highly frequent somatic mutations within the EGFR kinase domain $[4,5]$. As a contraindication, gefitinib possibly increases an adverse side effect affecting the lung, interstitial pneumonia, that can result in a fatal outcome within a short period of time [6]. Therefore, we need to establish a more accurate compass for the usage of gefitinib. Alternative therapeutic methods without adverse side effects also need to be developed. In this study, we first explored the mutations in EGFR along with lung cancer-associated genes such as KRAS, TP53, and ERBB2; the last encodes EGFR homologous protein [7]. To shed new light on the understanding of the molecular pathogenesis of lung cancer and to establish a novel therapeutic application, we examined the effects of siRNAmediated knockdown of EGFR and compared them with effects of gefitinib on lung cancer cells.

\section{Materials and Methods}

\section{Lung Cancer Tissues and Cell Lines and Their Mutation} Analyses

A total of 198 lung cancer specimens (all from Japanese patients; 139 males and 59 females; 106 adenocarcinomas, 52 squamous cell carcinomas, 20 large cell carcinomas, 12 small cell carcinomas, and 8 others) were analyzed for mutations at hot spots in the EGFR (exons 18, 19 and 21), ERBB2 (exon 20), TP53 (exons 5 through 8), and KRAS (exon 2) genes. In our series of 198 pa- tients, 18 cases (17 adenocarcinomas and 1 large cell carcinoma; 7 males and 11 females) were treated with gefitinib. Fresh-frozen primary tumor tissues were collected at the time of surgery and cut into pieces. Six-micrometer-thick sections were stained with hematoxylin and eosin and evaluated by microscopy to assess the percentage of neoplastic cells. Tumors with more than $80 \%$ neoplastic cellularity were microdissected. Genomic DNAs were isolated with a Qiagen DNAamp microkit (Qiagen, Valencia, Calif., USA) according to the manufacturer's instructions. Nucleotide sequences of the primer sets and the PCR conditions are summarized in table 1 , and the experiments were performed with the methods described by Sakurada et al. [8].

Six human lung adenocarcinoma cell lines were used for in vitro studies. A549, LK87, 11-18, and HT-1 were obtained from the Cell Resource Center for Biomedical Research (IDAC, Tohoku University, Sendai, Japan), PC-9 was provided by Dr. K. Nishio (National Cancer Center Research Institute, Tokyo, Japan), and H3255 was provided by Dr. P.A. Jänne (Dana Farber Cancer Institute, Boston, Mass., USA). All these cell lines were derived from lung adenocarcinoma cases. Cells were maintained by methods recommended by the suppliers. PC-9 and H3255 harbor mutations in EGFR (15-bp deletion and L858R, respectively), A549 and LK87 harbor mutations in KRAS (G12S and G12D, respectively), and 1118 and HT-1 harbor no mutations in either of these two genes.

siRNA Design and Transfection to Lung Cancer Cell Lines

We designed oligonucleotides for siRNA targeting against EGFR using the siDirect website (http://design.RNAi.jp) [9]; two pairs of siRNAs, termed 1565 and 1252, were purchased from Japan Bioservices (Asaka, Japan). These correspond to nucleotides $1565-1583$ and $1252-1270$ of EGFR, respectively, and the nucleotide sequences were 5'-GUCAGCCUGAACAUAACAU-3' and 5'-GUGUAACGGAAUAGGUAUU-3' in the sense strand. Both of the sense and corresponding antisense strands harbor two deoxyribonucleotides dTdT overhangs, and were annealed as previously described [10]. Then the siRNAs were transfected into the cell lines using the oligofectamine reagent (Invitrogen, Carlsbad, Calif., USA) according to the manufacturer's instructions. GL2 (the luciferase gene) siRNA was used as the experimental control as described previously [10]. 
Fig. 1. a Results of mutation analysis of the EGFR gene. Thirty-five patients had mutations: 25 in-frame deletion mutations and 10 point mutations. Del-3 was not reported previously and was deposited in DDBJ/ EMBL/GenBank databases under the accession No. AB221348. b Results of mutation analysis of the ERBB2 gene. Five patients had in-frame insertion mutations. All of the mutations were a simple duplication indicated by underlining. Ins- 2 and Ins-3 were not reported previously and were deposited in DDBJ/EMBL/GenBank databases under the accession No. AB221350 and AB221349, respectively.

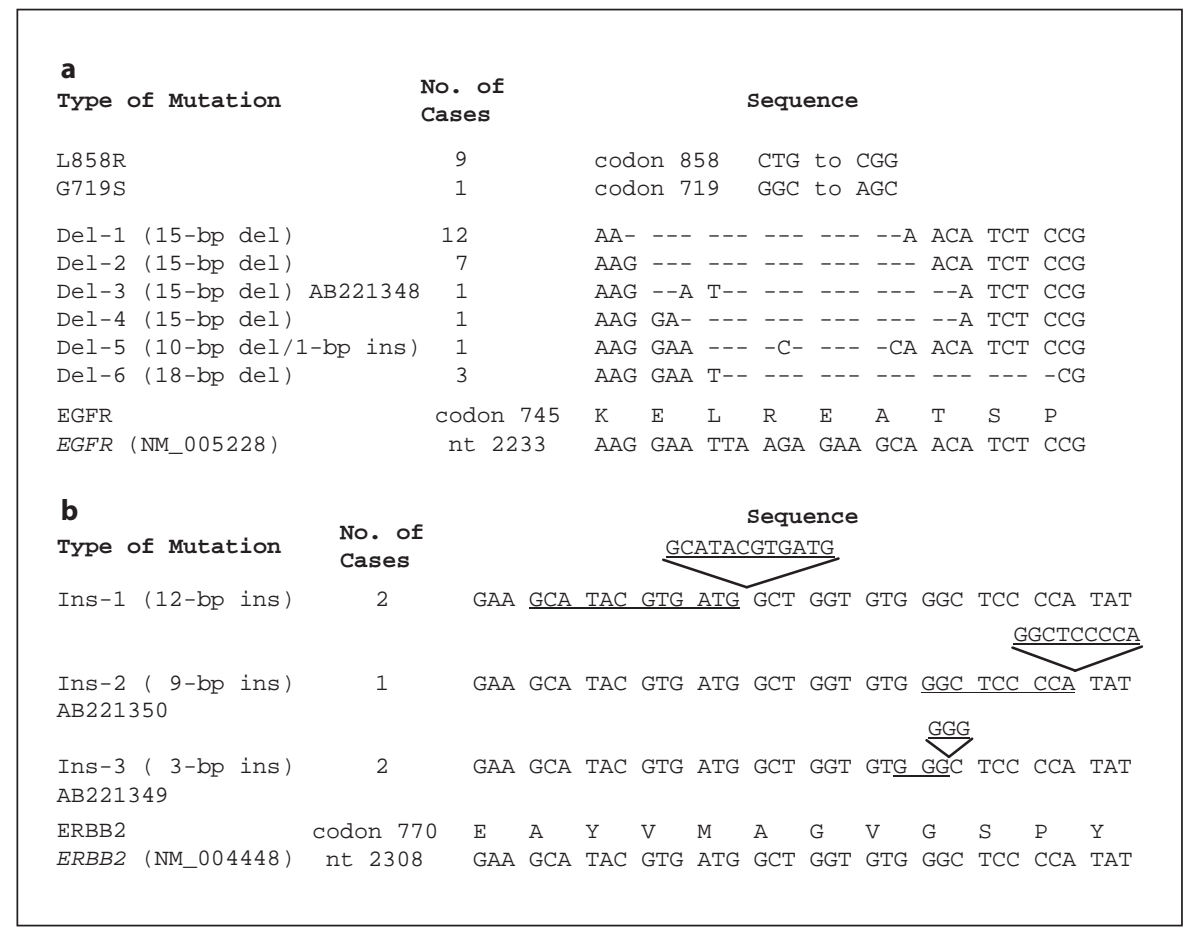

In vitro Growth Assay

A total of $5 \times 10^{3}$ cells were seeded in 96 -well plates. Then the medium was replaced with $100 \mu \mathrm{l}$ of $0.05 \%$ MTT/PBS(-) $72 \mathrm{~h}$ after addition of appropriate concentration of gefitinib or siRNA transfection. After an hour of incubation, the MTT solution was replaced with $100 \mu \mathrm{l}$ of $100 \%$ ethanol. The absorption of the cells that were completely suspended in ethanol was measured with a Versamax microplate reader (Amersham Bioscience). To monitor the cell growth with morphology, concurrent experiments with gefitinib or siRNA treatments were performed under the same concentrations.

\section{Western Blot Analysis}

Western blot analysis was performed as described previously [11]. The antibodies used were rabbit antihuman EGFR (Cell Signaling Technology, Beverly, Mass., USA) and mouse antihuman $\beta$-actin antibody (Sigma, St. Louis, Mo., USA); the latter was used as an internal control. The relative intensities of the signals were analyzed using the Luminescent Image Analyzer LAS-1000 Plus and Image Gauge 3.3 Software (FUJI Photo Film, Minamiashigara, Japan).

\section{Statistical Analysis}

All the in vitro experiments were performed in triplicate as indicated. A two-tailed Student t test computed by Stat View software 5.0 (SAS Institute, Cary, N.C., USA) was used to determine the statistical significance of measured differences. The statistical significance was established at $\mathrm{p}<0.05$.

\section{Results}

\section{Summary of Mutation Analyses}

Mutations in EGFR and ERBB2 were observed exclusively in adenocarcinomas: 35/106 (33\%) in EGFR and 5/106 (4.7\%) in ERBB2. Most of them were female nonsmokers (29/40, 73\%). Results are summarized in figure 1, in good agreement with previous reports [7, 12-14]. One EGFR mutation and two ERBB2 mutations were not reported previously, and were deposited in the DDBJ/EMBL/ GenBank databases under the accession No. AB221348AB221350. A mutually exclusive mutation between EGFR and KRAS was observed; all the 15 KRAS mutations were exclusively observed in 163 tumors without EGFR mutation ( $\mathrm{p}=0.048)$. On the other hand, no correlation between EGFR and TP53 was observed; 10 of 35 tumors with EGFR mutations also had mutations in TP53, and 353 of 905 human lung adenocarcinoma cases harbored the TP53 mutation according to the literature [15]. These results are consistent with previous ones $[12,16]$.

\section{Relationship between Response to Gefitinib and Mutation in Analyzed Genes}

Among the cases we analyzed, 18 patients were treated with gefitinib; of these, 9 had mutations in EGFR, and 1 had a mutation in ERBB2. All the cases with EGFR muta- 


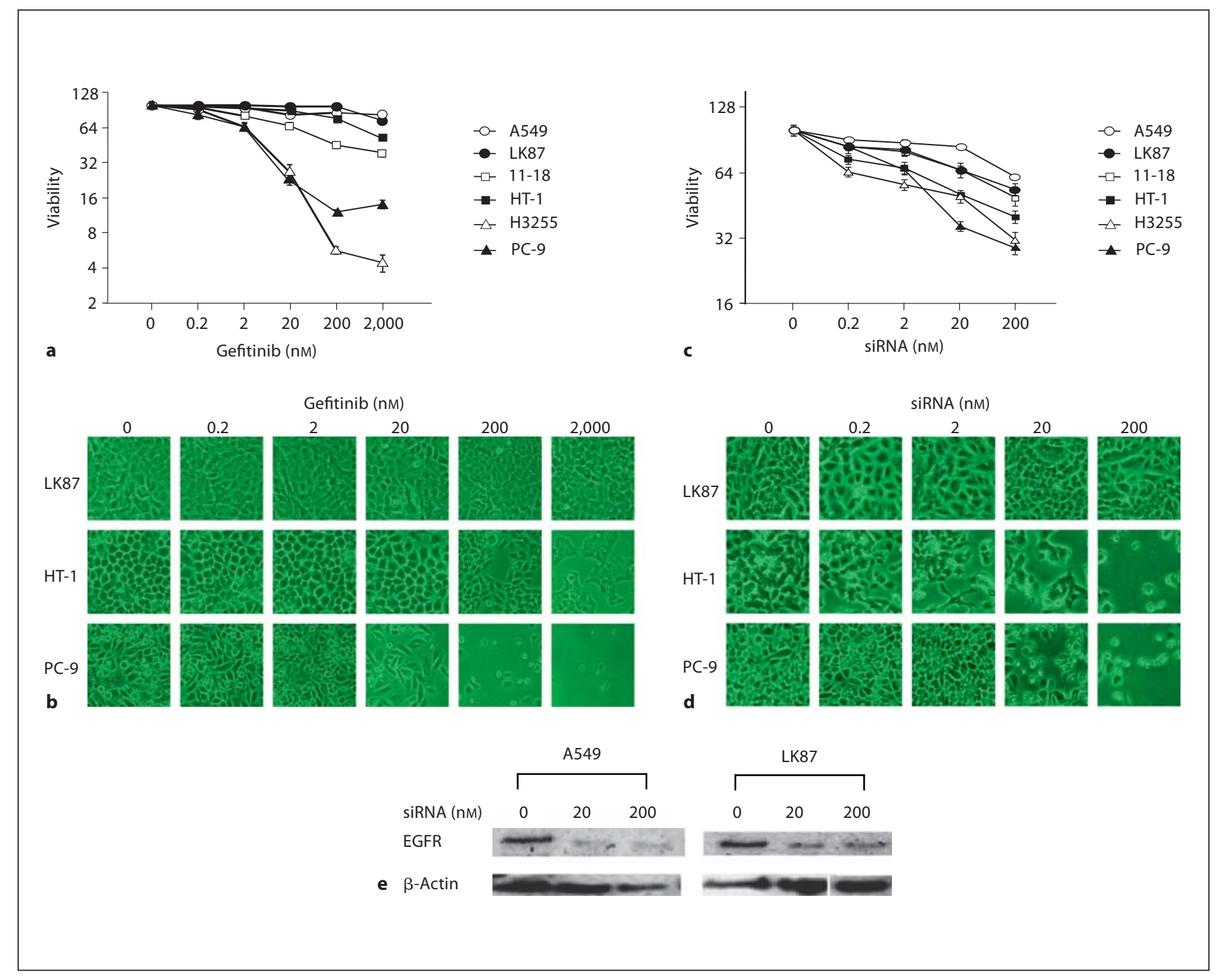

Fig. 2. a The human lung adenocarcinoma cell lines PC-9, H3255, A549, LK87, 11-18, and HT-1 were used. PC-9 and H3255 harbor mutations (Del-1 type 15-bp deletion and L858R, respectively) in EGFR. A549 and LK87 harbor mutations in KRAS (G12S and G12D, respectively) but not in EGFR, and 11-18 and HT-1 harbor no mutations in either of these two genes. MTT assay measured after $72 \mathrm{~h}$ culture in media with gefitinib. A total of $5 \times 10^{3}$ cells were seeded in 96-well plates, and $72 \mathrm{~h}$ after siRNA transfection or addition of appropriate concentration of gefitinib, the medium was replaced with $100 \mu \mathrm{l}$ of $0.05 \% \mathrm{MTT} / \mathrm{PBS}(-)$. After $1 \mathrm{~h}$ of incubation, the MTT solution was replaced with $100 \mu \mathrm{l}$ of $100 \%$ ethanol. The absorption of the cells that were completely suspended in ethanol was measured with a Versamax microplate reader (Amersham Bioscience). Results are plotted in a logarithmic manner. Concentration of gefitinib in culture medium is indicated below the horizontal axis. Viability indicated on the vertical axis represents the absorption ratio to cells without gefitinib. b Cells after $72 \mathrm{~h}$ culture in media with gefitinib are shown. LK87, HT-1, and PC-9 are representatives from the three groups: mutation with KRAS but not in EGFR, no mutations in either of these two genes, and mutation with EGFR. Surviving cells dramatically decrease in accordance with the increased gefitinib concentration in PC-9. HT-1 was moderately decreased, and LK87 was slightly decreased. In contrast, dead cells that are floating in media dramatically increased in accordance with the increased concentration of gefitinib in PC-9, and moderately increased in HT-1. A small number of floating dead cells were observed in LK87. c MTT assay measured after $72 \mathrm{~h}$ culture in medium with siRNA against EGFR. siRNA 1565 was used, and results are plotted in a logarithmic manner. Concentration of siRNA used for transfection is indicated below the horizontal axis. $\mathbf{d}$ Cells after $72 \mathrm{~h} \mathrm{cul-}$ ture in media with siRNA against EGFR are shown. The proportion of the surviving and dead cells showed in general the same tendency as the results after gefitinib treatment. e Western blot analyses after siRNA treatment targeting against EGFR are shown. The antibodies used were rabbit antihuman EGFR (Cell Signaling Technology, Beverly, Mass., USA) and mouse antihuman $\beta$-actin antibody (Sigma, St. Louis, Mo., USA); the latter was used as an internal control. Concentrations of siRNA are indicated above the lanes. 
tions had good responses to gefitinib; 6 of them were partial response and 2 were stable disease. One case initially responded to gefitinib, but then developed progressive disease and died. In 2 cases that we judged as stable disease, the apparent lung lesions were stable, but the abdominal lesions such as those in the para-aortic lymph node regressed in size. Hence gefitinib was more or less effective in lung adenocarcinoma patients with EGFR mutation. On the other hand, none of the cases without EGFR mutations responded markedly to gefitinib treatment. The efficacy of gefitinib was significantly different between cases with and without EGFR mutations ( $\mathrm{p}=$ 0.0008). One patient with a mutation in ERBB2 did not respond to gefitinib treatment.

\section{In vitro Studies Looking for Ideal Usage of Gefitinib}

To establish personalized medicine for lung cancer patients, we need to obtain more information about the appropriate use of gefitinib. To establish the ideal dosage of gefitinib, with minimum frequency of adverse side effects without decreasing the responsiveness of this drug, is one of the most important demands with the highest priority. For this purpose, we performed in vitro studies using human cancer cell lines with KRAS mutations (A549 and LK87), EGFR mutations (PC-9 and H3255), and without mutations in either KRAS or EGFR (11-87 and HT-1). An MTT assay measured after $72 \mathrm{~h}$ of culture in medium with gefitinib showed three clearly different patterns of growth curves (see fig. 2a). Cells with KRAS mutations did not show any apparent responsiveness to a high concentration of gefitinib ( $\mathrm{IC}_{50}>2 \mu \mathrm{M}$ ), but cells with EGFR mutations were responsive even to lower concentrations $\left(\mathrm{IC}_{50}\right.$ is about $5 \mathrm{nM}$ ). Gefitinib was also effective against cells without mutations in either KRAS or EGFR when the concentration was increased ( $\mathrm{IC}_{50}$ is about $\left.2 \mu \mathrm{M}\right)$. Typical examples of the three different types of cells after gefitinib treatment are shown in figure $2 \mathrm{~b}$; the results are very consistent with those with the MTT assay.

\section{Effects of siRNA-Mediated Knockdown against EGFR}

To study whether or not the knockdown of EGFR has the same effects on cancer cells as gefitinib, we performed siRNA experiments to observe the effects on the in vitro growth of several human lung cancer cell lines. We designed two siRNAs: because the efficiency of siRNA 1565 was slightly better than siRNA 1252 although the results were basically the same, we used siRNA 1565 for further experiments. The growth curve we obtained showed the expected results; as shown in figure 2c, cells with EGFR mutations were very sensitive to the EGFR knockdown
( $\mathrm{IC}_{50}$ is about $10 \mathrm{nM}$ ), those without mutations in either EGFR or KRAS were moderately sensitive ( IC $_{50}$ is about $200 \mathrm{nM}$ ), and those with KRAS mutations were poorly sensitive $\left(\mathrm{IC}_{50}>200 \mathrm{nM}\right)$. Typical examples of the three different types of cells after siRNA treatment are shown in figure 2d; the results were very consistent with those of the MTT assay. We observed no growth suppression by GL2 siRNA treatment in the cells used (data not shown). When we monitored the efficiency of siRNA intake, we analyzed surviving cells by Western blot analysis; the expression of EGFR protein was markedly suppressed in cells without EGFR mutations (see fig. 2e). In the cells with EGFR mutations, it was not possible to monitor the EGFR protein level after siRNA treatment because of the immediate death of most of the transfected cells.

\section{Discussion}

Gefitinib interacts with the EGFR protein and inhibits the tyrosine kinase activity by binding to the ATP binding cleft of the tyrosine kinase domain [3]. Several reports have suggested that gefitinib harbors a valuable antitumor activity, and there is the promising possibility that it is a novel treatment option for patients with advanced non-small cell lung cancer, especially adenocarcinoma $[2,3,17-19]$. However, the use of this drug is controversial; some reports support and others deny a benefit for lung cancer patients. In our series of patients, 18 were treated with gefitinib; all the cases with EGFR mutations showed tumor regression after gefitinib administration. On the other hand, none of the cases without EGFR mutations responded markedly to gefitinib treatment. These results suggest the importance of checking EGFR mutation status before administration of gefitinib.

ERBB2 is one of the EGFR kinase subfamilies, and the ERBB2 mutation was reported at a frequency of $9.8 \%$ $(5 / 51)$ in lung adenocarcinoma [7]. Although this frequency is lower than that of EGFR, it is likely that these mutations also play important roles in the pathogenesis of lung adenocarcinomas. However, the effectiveness of gefitinib against tumors with ERBB2 mutations is not clear in this study; only one case was treated with gefitinib and did not respond to the drug. We did not have any lung cancer cell lines with mutations in ERBB2, so it was not possible to further analyze the sensitivity of such mutations to gefitinib and siRNA-mediated knockdown.

Mutations of EGFR and KRAS were mutually exclusive, consistent with previous reports $[12,16]$. TP53, how- 
ever, did not show any association with EGFR mutations. These results may reflect one of the aspects of the differing molecular pathogeneses of lung adenocarcinomas. This evidence is reasonable; KRAS is on the downstream of EGFR in the MAPK cascade, and activation of one of these molecules should be enough for upregulation of cell growth mediated by MAPK cascade. Hence tumors with activated KRAS do not require activated EGFR in their tumorigeneses, and gefitinib will not be effective against tumors with KRAS mutations. Indeed, such cells were very resistant to gefitinib treatments.

A previous in vitro study showed that there were more than 10 -fold differences in the effective dose of gefitinib in resistant and sensitive cell lines [20]. In our study however, the $\mathrm{IC}_{50}$ for cells with EGFR mutations was less than that for other cells by 400 -fold or more. Our results may have implied a possibility that a lower concentration of gefitinib is enough to suppress the growth in cells with EGFR mutations. The present clinical dose of $250 \mathrm{mg} / \mathrm{day}$, resulting in mean steady-state plasma concentrations of 400-1,400 nM [21], could be excessive for cases with EGFR mutations (see fig. 2a, b); $200 \mathrm{nM}$ is enough in these two cells with EGFR mutation. To avoid the various adverse side effects of gefitinib, our data imply that the ideal dose of gefitinib can be settled depending on the mutation status. Second, it is possibe that an increased dose of gefitinib lowers the viability of cells without EGFR mutations, particularly those also without a KRAS mutation. Third, cells with KRAS mutations probably do not have a beneficial response to gefitinib intake. Decreasing the amount of gefitinib will probably reduce the fatal adverse effects of the medication such as interstitial pneumonia. Because the risk factors for such adverse side effects are not clearly understood at present, decreasing the dose of gefitinib will surely help reduce the incidence of lethal side effects.

In the present study, we considered the possibility of better alternative therapies other than gefitinib and tested siRNA-mediated EGFR knockdown. Our MTT assay demonstrated promising possibilities for siRNA treatment; cells with the EGFR mutation responded well, similarly to their response to gefitinib treatment. Furthermore, cells without mutations in EGFR and KRAS showed moderate sensitivities to siRNA-mediated EGFR knockdown. It is notable that cells with KRAS mutation were also slightly sensitive to EGFR knockdown. The possibility that siRNA-mediated knockdown may provide a novel method for the treatment of lung adenocarcinoma includes the hope that it may prevent adverse side effects such as interstitial pneumonia. There is also a possibility that siRNA-mediated knockdown might show synergistic enhancement with other anticancer drugs as was observed in other human cancer [10]. However, we need further investigation to overcome the hurdles for clinical application including the delivery system or effects on tissues other than tumor.

Recently, the second point mutation of T790M in EGFR, and also D761Y, led to losing the gefitinib sensitivity [22-24]. The T790M mutation leads to the steric hindrance of $E G F R$ inhibitor binding, owing to the presence of the bulkier methionine side chain in the ATP-kinase binding pocket [22]. The siRNA-mediated knockdown of EGFR has the possibility of being effective even for cases with acquisition of additional EGFR mutations that cause gefitinib resistance, as long as without KRAS mutation, because the RNAi interaction is not affected by the structural change of protein.

Cells without EGFR mutation also showed some sensitivity to siRNA, although the sensitivity was lower than that with EGFR mutations. A previous report of siRNA targeting against EGFR failed to suppress the growth of cancer cells with a wild-type EGFR gene [20], but our present siRNA results may provide the option of a novel and effective treatment for such cancer patients. The reasons for these differences are not clear, but some factors such as differences in target sequences or the mutation status of KRAS in the studied cells may have been involved.

In this report, we have suggested that the aspects of EGFR mutations are significant characteristics of Japanese lung adenocarcinoma patients and indicated the importance of considering the mutation status of tumor when calculating the administration dose of gefitinib. Additionally, we discussed the possibility of the RNAi technique for in vivo abrogation of the progression in lung cancer.

\section{Acknowledgments}

We are grateful to Dr. K. Nishio (National Cancer Center Research Institute, Tokyo, Japan) and P.A. Jänne (Dana Farber Cancer Institute, Boston, Mass., USA) for providing the cell lines PC-9 and H3255, respectively, to Dr. B.L.S. Pierce (University of Maryland University College, East Adelphi, Md., USA) for editorial work in the preparation of the manuscript, and to M. Nanjo for her secretarial assistance. This work was supported in part by Grants-in-Aid and the 21st Century COE Program Special Research Grant from the Ministry of Education, Culture, Sports, Science and Technology of Japan, and by a Grant-in-Aid for Cancer Research from the Ministry of Health, Labour and Welfare of Japan. 


\section{References}

1 Parkin DM, Pisani P, Ferlay J: Estimates of the worldwide incidence of 25 major cancers in 1990. Int J Cancer 1999;80:827-841.

-2 Fukuoka M, Yano S, Giaccone G, Tamura T, Nakagawa K, Douillard JY, Nishiwaki Y, Vansteenkiste J, Kudoh S, Rischin D, Eek R, Horai T, Noda K, Takata I, Smit E, Averbuch S, Macleod A, Feyereislova A, Dong RP, Baselga J: Multi-institutional randomized phase II trial of gefitinib for previously treated patients with advanced non-small-cell lung cancer. J Clin Oncol 2003;21:23372346.

3 Cohen MH, Williams GA, Sridhara R, Chen G, McGuinn WD Jr, Morse D, Abraham S, Rahman A, Liang C, Lostritto R, Baird A, Pazdur R: United States Food and Drug Administration drug approval summary: gefitinib (ZD1839, 'Iressa') tablets. Clin Cancer Res 2004;10:1212-1218.

4 Lynch TJ, Bell DW, Sordella R, Gurubhagavatula $S$, Okimoto RA, Brannigan BW, Harris PL, Haserlat SM, Supko JG, Haluska FG, Louis DN, Christiani DC, Settleman J, Haber DA: Activating mutation in the epidermal growth factor receptor underlying responsiveness of non-small-cell lung cancer to gefitinib. N Engl J Med 2004;350:2129-2139.

$\checkmark 5$ Paez JG, Jänne PA, Lee JC, Tracy S, Greulich H, Gabriel S, Herman P, Kaye FJ, Lindeman N, Boggon TJ, Naoki K, Sasaki H, Fujii Y, Eck MJ, Sellers WR, Johnson BE, Meyerson M: EGFR mutations in lung cancer: correlation with clinical response to gefitinib therapy. Science 2004;304:1497-1500.

6 Inoue A, Saijo Y, Maemondo M, Gomi K, Tokue Y, Kimura Y, Ebina M, Kikuchi T, Moriya T, Nukiwa T: Severe acute interstitial pneumonia and gefitinib. Lancet 2004;361: 137-139.

7 Stephens P, Hunter C, Bignell G, Edkins S, Davies H, Teague J, Stevens C, O’Meara S, Smith R, Parker A, Barthorpe A, Blow M, Brackenbury L, Butler A, Clarke O, Cole J, Dicks E, Dike A, Drozd A, Edwards K, Forbes S, Foster R, Gray K, Greenman C, Halliday K, Hills K, Kosmidou V, Lugg R, Menzies A, Perry J, Petty R, Raine K, Ratford L, Shepherd R, Small A, Stephens Y, Tofts C, Varian J, West S, Widaa S, Yates A, Brasseur F, Cooper CS, Flanagan AM, Knowles M, Leung SY, Louis DN, Looijenga LH, Malkowicz B, Pierotti MA, Teh B, Chenevix-Trench G, Weber BL, Yuen ST, Harris G, Goldstraw P, Nicholson AG, Futreal PA, Wooster R, Stratton MR: Intragenic ERBB2 kinase mutations in tumors. Nature 2004;431:525-526.
-8 Sakurada A, Suzuki A, Sato M, Yamakawa H, Orikasa K, Uyeno S, Ono T, Ohuchi N, Fujimura S, Horii A: Infrequent genetic alterations of the PTEN/MMAC1 gene in Japanese patients with primary cancers of the breast, lung, pancreas, kidney, and ovary. Jpn J Cancer Res 1997;88:1025-1028.

$\checkmark$ Naito Y, Yamada T, Ui-Tei K, Morishita S, Saigo K: siDirect: Highly effective, targetspecific siRNA design software for mammalian RNA interference. Nucleic Acids Res 2004;32:W124-W129.

10 Hata T, Furukawa T, Sunamura M, Egawa S, Motoi F, Ohmura N, Marumoto T, Saya H, Horii A: RNA interference targeting aurora kinase A suppresses tumor growth and enhances the taxane chemosensitivity in human pancreatic cancer cells. Cancer Res 2005;65:2899-2905

11 Kondo E, Horii A, Fukushige S: The human PMS2L proteins do not interact with hMLH1, a major DNA mismatch repair protein. J Biochem 1999;125:818-825.

12 Kosaka T, Yatabe Y, Endoh H, Kuwano H, Takahashi T, Mitsudomi T: Mutation of the epidermal growth factor receptor gene in lung cancer: biological and clinical implications. Cancer Res 2004;64:8919-8923.

13 Pao W, Miller V, Zakowski M, Doherty J, Politi K, Sarkaria I, Singh B, Heelan R, Rusch V, Fulton L, Mardis E, Kupfer D, Wilson R, Kris M, Varmus H: EGF receptor gene mutations are common in lung cancers from 'never smokers' and are associated with sensitivity of tumors and erlotinib. Proc Natl Acad Sci USA 2004;101:13306-13311.

$14 \mathrm{Mu}$ XL, Li LY, Zhang XT, Wang MZ, Feng RE, Cui QC, Zhou HS, Guo BQ: Gefitinibsensitive mutations of the epidermal growth factor receptor tyrosine kinase domain in Chinese patients with non-small cell lung cancer. Clin Cancer Res 2005;11:42894294.

15 Steels E, Paesmans M, Berghmans T, Branle F, Lemaitre F, Mascaux C, Meert AP, Steels E, Vallot F, Lafitte JJ: Role of p53 as a prognostic factor for survival in lung cancer: a systematic review of the literature with a meta-analysis. Eur Respir J 2001;18:705719.

16 Marchetti A, Martella C, Felicioni L, Barassi F, Salvatore S, Chella A, Camplese PP, Iarussi T, Mucilli F, Mezzetti A, Cuccurullo F, Sacco R, Buttitta F: EGFR mutations in nonsmall-cell lung cancer: analysis of a large series of cases and development of a rapid and sensitive method for diagnostic screening with potential implication on pharmacologic treatment. J Clin Oncol 2005;23:857865 .
17 Sirotnak FM, Zakowski MF, Miller VA, Scher HI, Kris MG: Efficacy of cytotoxic agents against human tumor xenografts is markedly enhanced by coadministration of ZD1839 (Iressa), an inhibitory of EGFR tyrosine kinase. Clin Cancer Res 2000;6:48854892.

18 Kris MG, Natale RB, Lynch TJ Jr, Prager D, Belani CP, Schiller JH, Kelly K, Spiridonidis H, Sandler A, Albain KS, Cella D, Wolf MK, Averbuch SD, Ochs JJ, Kay AC: Efficacy of gefitinib, an inhibitor of the epidermal growth factor receptor tyrosine kinase, in symptomatic patients with non-small cell lung cancer: a randomized trial. JAMA 2003; 290:2149-2158.

19 Jänne PA, Gurubhagavatula S, Yeap BY, Lucca J, Ostler P, Skarin AT, Fidias P, Lynch TJ, Johnson BE: Outcomes of patients with advanced non-small cell lung cancer treated with gefitinib (ZD1839, 'Iressa') on an expanded access study. Lung Cancer 2004;44: 221-230.

20 Sordella R, Bell DW, Haber DA, Settleman J: Gefitinib-sensitizing EGFR mutations in lung cancer activate anti-apoptotic pathways. Science 2004;305:1163-1167.

-21 Albanell J, Rojo F, Averbuch S, Feyereislova A, Mascaro JM, Herbst R, LoRusso P, Rischin D, Sauleda S, Gee J, Nicholson RI, Baselga J: Pharmacodynamic studies of the epidermal growth factor receptor inhibitor ZD1839 in skin from cancer patients: histopathologic and molecular consequences of receptor inhibition. J Clin Oncol 2002;20:110-124.

$>22$ Kobayashi S, Boggon TJ, Dayaram T, Jänne PA, Kocher O, Meyerson M, Johnson BE, Eck MJ, Tenen DG, Halmos B: EGFR mutation and resistance of non-small-cell lung cancer to gefitinib. N Eng J Med 2005;352:786792.

23 Pao W, Miller VA, Politi KA, Riely GJ, Somwar R, Zakowski MF, Kris MG, Varmus H: Acquired resistance of lung adenocarcinomas to gefitinib or erlotinib is associated with a second mutation in the EGFR kinase domain. PLoS Med 2005;2:e73.

24 Balak MN, Gong Y, Riely GJ, Somwar R, Li AR, Zakowski MF, Chiang A, Yang G, Ouerfelli O, Kris MG, Ladanyi M, Miller VA, Pao W: Novel D761Y and common secondary T790M mutations in epidermal growth factor receptor-mutant lung adenocarcinomas with acquired resistance to kinase inhibitors. Clin Cancer Res 2006;12:6494-6501. 